\title{
Educação permanente em alimentação e nutrição na Estratégia Saúde da Família: encontros e desencontros em municípios brasileiros de grande porte
}

\author{
Ongoing food and nutrition education \\ within the family health strategy: points of agreement \\ and disagreement in major Brazilian cities
}

Luciani Martins Ricardi ${ }^{1}$ Maria Fátima de Sousa ${ }^{1}$
${ }^{1}$ Programa de PósGraduação em Saúde Coletiva, Faculdade de Ciências da Saúde, Universidade de Brasília. Campus Universitário Darcy Ribeiro, Asa Norte. 70910900 Brasília DF Brasil. luciani_snp@hotmail.com
Abstract This study sought to ascertain the facilitating and inhibiting factors and strategies used by 28 major Brazilian cities in conducting ongoing food and nutrition education within the Family Health Strategy. It involved a qualitative study of multiple cases. The data collection technique was conducted in interviews with municipal coordinators of food and nutrition campaigns from the five regions of the country. The study was conducted between 2009 and 2010. NVivo 10 software was used and content analysis was divided up into thematic categories. Forty-four professionals were interviewed, 19 of which were nutritionists. Most cities were from the Northeast and Southeast; 14 were capitals, 7 were metropolises and 14 had Family Health Suppor Units. The most frequently mentioned facilitating factors for Ongoing Education in Nutrition were partnerships and the availability of funds. The most frequent inhibiting factors were difficulty in scheduling and a lack of professionals in management of nutrition actions. The strategies most commonly used were conducting training at the local level, in groups and planning and programming. The conclusion drawn is that more investment is needed for Ongoing Education in Feeding and Nutrition to be effectively implemented.

Key words Food, Nutrition, Public health, Training, Health personnel, Family health program, Primary health care
Resumo O objetivo foi conhecer fatores facilitadores e dificultadores e estratégias utilizadas por 28 municípios brasileiros de grande porte na realização de Educação Permanente em alimentação e nutrição, na Estratégia Saúde da Família. Método qualitativo de múltiplos casos. A técnica de coleta de dados foi a entrevista com coordenadores municipais das ações de alimentação e nutrição, das cinco regiões do país. O estudo foi realizado entre 2009 e 2010. Utilizou-se o software NVivo e a análise de conteúdo foi orientada por categorias temáticas. Foram entrevistados 44 profissionais, sendo 19 nutricionistas. A maioria dos municípios era do Nordeste e Sudeste, 14 eram capitais, 7 metrópoles e 14 tinham Núcleo de Apoio à Saúde da Família. Os fatores facilitadores para Educação Permanente em nutrição mais citados foram as parcerias e a disponibilidade de recursos. Os dificultadores mais frequentes foram a indisponibilidade de agendas e a falta de profissionais na gestão das ações de nutrição. As estratégias mais utilizadas foram a realização de ações educativas no nível local, por grupos e o planejamento e programação. Concluiu-se que são necessários maiores investimentos para que a Educação Permanente em alimentação e nutrição se concretize.

Palavras-chave Alimentação, Nutrição em saúde pública, Capacitação, Pessoal de saúde, Programa Saúde da Família, Atenção Primária à Saúde 


\section{Introdução}

As características e o modo de vida das populações refletem diretamente em suas condições de saúde e doença. Assim, a Atenção Básica à Saúde (AB) deve ser o contato preferencial dos usuários com o Sistema Único de Saúde (SUS), uma vez que é desenvolvida com alto grau de descentralização e capilaridade, ocorrendo no local mais próximo da vida das pessoas ${ }^{1}$. Para a qualificação desse nível de atenção e o fortalecimento do vínculo entre os profissionais de saúde e a comunida$\mathrm{de}^{2}$, a Estratégia Saúde da Família (ESF) é a forma prioritária de reorganização dos serviços da $\mathrm{AB}$.

$\mathrm{Na}$ busca pela melhoria da qualidade de vida da população, a partir do princípio da integralidade, as ações de alimentação e nutrição, como componente do trabalho interdisciplinar, são indispensáveis ${ }^{3,4}$. Para isso, a elaboração e a pactuação de uma agenda integrada de educação alimentar e nutricional, intra e intersetorial, deve ser uma prioridade 5 .

Além disso, para um cuidado nutricional efetivo, os profissionais de saúde precisam estar qualificados e o serviço de saúde deve estar organizado de forma a permitir um processo constante de formação $0^{6}$. A capacitação é uma das estratégias mais utilizadas para enfrentar os problemas de desenvolvimento dos serviços de saúde. Porém, embora toda capacitação vise à melhoria do desempenho do pessoal, nem toda ação de capacitação representa parte substantiva de uma estratégia de mudança institucional, ou seja, nem sempre resulta em um processo de educação permanente ${ }^{7}$.

A Educação Permanente em Saúde é uma estratégia sistemática e global, que visa à transformação das práticas profissionais e da própria organização do trabalho, sendo fundamental para que o local de trabalho venha a ser um espaço de atuação crítica, reflexiva, propositiva, compromissada e tecnicamente competente. Nesse processo, promove-se uma ampla intersecção entre saúde e educação, no que tange à formação, gestão, atenção e participação ${ }^{7,8}$. Uma das finalidades da Educação Permanente é, justamente, a contribuição para que cada grupo possa adquirir a capacidade de ser o seu próprio coautor, em meio a um processo de reinvenção das instituições de saúde ${ }^{9}$.

Assim, o objetivo desse estudo foi conhecer os fatores facilitadores e dificultadores e as estratégias utilizadas por 28 municípios brasileiros de grande porte na realização de ações de Educação Permanente em alimentação e nutrição, na Estratégia Saúde da Família.

\section{Métodos}

Este estudo é um extrato da pesquisa Estudo sobre o processo de organização da Atenção Básica: análise da inserção da Estratégia de Saúde da Família em municípios brasileiros de grande porte e do desenvolvimento das ações de alimentação e nutrição, coordenada pelo Núcleo de Estudos de Saúde Pública e desenhada em parceria com o Observatório de Políticas de Segurança Alimentar e Nutrição, ambos da Universidade de Brasília, a qual foi realizada entre os anos de 2009 e 2011. É parte também da dissertação de mestrado da primeira autora. O projeto foi financiado pelo Ministério da Ciência, Tecnologia e Inovação.

Utilizou-se a abordagem qualitativa, com a realização de estudo de múltiplos $\operatorname{casos}^{10}$. Participaram do estudo apenas municípios de grande porte - com população igual ou maior que 100 mil habitantes - que tinham equipes da Estratégia Saúde da Família. Dentre os 55 municípios selecionados para a composição da amostra da pesquisa maior, calculada por meio de cálculo amostral aleatório estratificado em dois estágios, neste estudo foram selecionados 28. Para considerar a variabilidade, foram selecionados municípios de todas as regiões do país, capitais e do interior dos estados, de grande porte e metrópoles, com e sem Núcleo de Apoio à Saúde da Família (NASF) e com cobertura de ESF maior e menor que $50 \%$.

Os municípios foram visitados por pesquisadores, em dupla, previamente treinados, entre dezembro de 2009 e agosto de 2010 e foram entrevistados os coordenadores municipais das ações de alimentação e nutrição. O roteiro para a entrevista semiestruturada foi testado em um Piloto realizado em dois municípios de grande porte que não entraram na amostra. Em relação às ações de educação permanente em alimentação e nutrição, as questões norteadoras eram referentes à realização, à frequência das atividades, às estratégias, à percepção do coordenador e às dificuldades encontradas. As entrevistas foram gravadas e transcritas literalmente (Ipsis verbis).

A análise dos dados foi feita por meio da Análise de Conteúdo por categorias temáticas, criadas a posteri, com base em Bardin ${ }^{11}$. Utilizou-se o software Qualitative Solutions Research NVivo, versão $10^{12}$, para auxiliar na organização dos dados e na categorização. Neste artigo, são apresentados os resultados das categorias "Fatores facilitadores", "Fatores dificultadores" e "Estratégias utilizadas na Educação Permanente" em alimentação e nutrição. As codificações foram 
feitas a partir de unidades de registro e os trechos selecionados para a ilustração são as unidades de contexto.

A pesquisa foi aprovada pelo Comitê de Ética em Pesquisa com Seres Humanos da Faculdade de Ciências da Saúde, da Universidade de Brasília. Todos os entrevistados assinaram o Termo de Consentimento Livre e Esclarecido. O anonimato dos participantes foi assegurado e, na citação das falas, foram utilizadas siglas, com base na região do país na qual o município está localizado (CO para Centro-Oeste; N para Norte; NE para Nordeste; S para Sul e SE para Sudeste). Quando havia citação de nomes nos trechos, os mesmos eram substituídos pelo termo "Fulano (a)".

\section{Resultados e discussão}

\section{Caracterização dos entrevistados e dos municípios e categorização}

Foram entrevistados 44 profissionais, dos quais 19 eram nutricionistas e 40 do sexo feminino. A média de tempo no cargo foi de 48 meses. Dos 28 municípios, quanto às regiões, 11 eram do Nordeste, sete do Sudeste, quatro do Sul, quatro do Centro-Oeste e dois do Norte. Além disso, 14 eram capitais, sendo sete metrópoles, e 14 tinham NASF.

A Tabela 1 apresenta o número de citações de cada categoria e subcategoria, bem como o número de municípios que fizeram menção aos fatores facilitadores e dificultadores e às estratégias para a EP em alimentação e nutrição.

Observa-se que nem todos os entrevistados dos municípios mencionaram as categorias. Os fatores facilitadores mais frequentes para a realização de ações de EP sobre o tema de alimentação e nutrição foram as parcerias e a disponibilidade de recursos. Já os fatores dificultadores mais citados foram a indisponibilidade de agenda e a falta de profissionais na gestão das ações de alimentação e nutrição. Quanto às estratégias utilizadas, a realização de ações no nível local, por grupos e o planejamento e programação foram as mais mencionadas. Subcategorias com apenas uma ou duas citações foram agrupadas em "Outros".

$\mathrm{Na}$ fala dos entrevistados, percebe-se que há uma mescla dos conceitos de Educação Continuada, de capacitação e de Educação Permanente, uma vez que, em muitos municípios, ainda não há um processo de Educação Permanente sistemático e estruturado, mas sim capacitações ou treinamentos pontuais, baseados em temas es-
Tabela 1. Fatores facilitadores e dificultadores e estratégias utilizadas por 28 municípios brasileiros de grande porte na realização de Educação Permanente em alimentação e nutrição, na Estratégia Saúde da Família $2009 / 2010$

\begin{tabular}{|c|c|c|}
\hline Categorias & Citações & Municípios \\
\hline Fatores Facilitadores & 70 & 22 \\
\hline Parcerias & 27 & 11 \\
\hline Disponibilidade de Recursos & 18 & 10 \\
\hline Adesão dos profissionais & 5 & 2 \\
\hline Incentivo às ações & 5 & 4 \\
\hline Formação de tutores & 4 & 3 \\
\hline Setor de Educação Permanente em Saúde & 4 & 4 \\
\hline Outros ${ }^{*}$ & 7 & 6 \\
\hline Fatores Dificultadores & 59 & 19 \\
\hline Indisponibilidade de agenda & 17 & 12 \\
\hline Falta de profissionais na gestão & 12 & 6 \\
\hline Falta de nutricionistas & 5 & 4 \\
\hline Ausência de estratégias & 4 & 3 \\
\hline Rotatividade de profissionais & 4 & 3 \\
\hline Trâmites para gastar o dinheiro & 4 & 3 \\
\hline Adesão dos profissionais & 3 & 3 \\
\hline Falta de infraestrutura & 3 & 3 \\
\hline Outros & 7 & 4 \\
\hline Estratégias utilizadas na Educação Permanente & 83 & 20 \\
\hline A partir do nível local & 14 & 10 \\
\hline Planejamento e programação & 9 & 5 \\
\hline Atividades de educação por grupos & 8 & 6 \\
\hline Avaliação e monitoramento & 7 & 5 \\
\hline Capacitação teórica e apoio técnico & 6 & 4 \\
\hline Feedback & 6 & 1 \\
\hline Existência de estratégias & 6 & 5 \\
\hline Metodologias mais ativas & 4 & 3 \\
\hline Foco nos Agentes Comunitários de Saúde & 3 & 1 \\
\hline Outros $^{*}$ & 20 & 12 \\
\hline
\end{tabular}

"Subcategorias com apenas uma ou duas citações agrupadas. Fonte: As autoras.

pecíficos, ou, no caso da Educação Continuada, investimentos mais voltados para o indivíduo, como as especializações.

\section{Fatores facilitadores para a Educação Permanente em alimentação e nutrição}

Em relação aos fatores facilitadores, foram identificadas seis subcategorias principais. A realização de parcerias, fator facilitador mais mencionado para o desenvolvimento de ações de qualificação em alimentação e nutrição, ocorre principalmente com a Universidade, segundo os entrevistados. SE6 menciona a atuação da Academia na formação do Agente Comunitário de Saúde (ACS).

[...] é uma faculdade que tem o curso de nutrição também. Então, fica a professora, com a es- 
tagiária, diretamente com essas equipes. Elas trabalham a questão da formação do agente comunitário, tanto em aferição antropométrica, como em alimentação saudável, e trabalham também com a comunidade. (SE6)

Já na fala de outros coordenadores, observase claramente a relação entre a Universidade e a implantação dos NASF, programa ainda recente na data das entrevistas. Ressalta-se que a atuação dos profissionais dos NASF vai ao encontro dos ideais da EP, uma vez que eles participam, no processo de matriciamento, da instrumentalização dos profissionais da ESF para o desenvolvimento de ações integrais, numa construção coletiva de conhecimento mais autônomo baseado na realidade local ${ }^{5}$.

As capacitações para os profissionais nutricionistas, elas, desde o início do NASF, elas foram oferecidas na parceria com as universidades, principalmente com a Universidade Federal. (SE1)

[...] agora, com a residência multiprofissional no Saúde da Família, nós temos uma residente nutricionista e a proposta de atuação nessa residência é de apoio matricial, é a proposta do NASF que nós estamos adaptando para a nossa realidade aqui. (CO4)

Essa interação entre ensino, pesquisa e serviço tem se mostrado fundamental, principalmente no que se refere aos processos de educação permanente. Como destacado por Ceccim e Feuerwerker ${ }^{13}$, a educação permanente em saúde, incorporada ao cotidiano da gestão setorial e da condução gerencial dos serviços de saúde, coloca o SUS, para além de um mero campo de estágio ou aprendizagem prática, como um interlocutor nato das instituições formadoras, na formulação e implementação dos projetos político-pedagógicos na formação profissional.

A Política Nacional de Alimentação e Nutrição (PNAN) ${ }^{5}$ também ressalta que a articulação dos gestores com as instituições formadoras é um dispositivo importante para a qualificação da força de trabalho para gestão e atenção nutricional, para desenvolvimento de projetos de formação em serviço, pesquisa na rede de atenção à saúde do SUS e campos para extensão. Nesse sentido, tem-se avançado com programas que visam à mudança na formação profissional na área da saúde, como o Pró-Saúde, instituído em 2005, e o PET-Saúde, instituído em $2010^{14,15}$.

Também os Centros Colaboradores de Alimentação e Nutrição (CECAN), compostos por dez universidades federais, buscam integrar ensino, pesquisa e serviço, configurando uma rede de apoio às ações de alimentação em nutrição nas cinco regiões brasileiras. Uma importante contribuição dos centros é a disseminação dos princípios do SUS, da PNAN e da $\mathrm{AB}^{16}$.

Além disso, as Escolas Técnicas de Saúde do SUS, segundo os entrevistados, também são importantes parcerias para a formação dos profissionais, em especial do ACS.

$E$ aí nós estaremos realizando agora, através da Escola Técnica do SUS, todo o material está montado, então vai ser um curso com duração aproximada de seis meses [...]. (NE10)

As Escolas Técnicas do SUS são instituições públicas criadas, a partir de 1980, para qualificar e formar os trabalhadores do SUS, de nível fundamental e médio, que não possuíam qualificação específica para as funções que desempenhavam. Atualmente, o trabalho dessas instituições de ensino é focado na formação de recursos humanos de nível médio, tomando as práticas em saúde como referência e incorporando as necessidades de saúde e o perfil epidemiológico da população ao processo educativo ${ }^{17}$.

Outro aliado para as ações de qualificação dos ACS mencionado foi o Serviço Social da Indústria (SESI), por meio do programa Cozinha Brasil. Nesse caso, a ação foi pontual, em um contexto de capacitação, não necessariamente envolvida em um contexto amplo de EP.

Por exemplo, a gente fez uma parceria no ano passado, a gente, foram pontuais, mas a gente, já em dois anos seguidos, a Secretaria fez uma parceria com o SESI (Serviço Social da Indústria), a Cozinha Brasil, em que a gente levou esse treinamento para todos os agentes comunitários, são 1.300 agentes comunitários, e para as merendeiras das creches e de escolas. Então, a Mesa foi programada para que a gente levasse para todas as unidades de saúde. (CO2)

$\mathrm{O}$ segundo fator facilitador mais mencionado pelos entrevistados foi a disponibilidade de recursos para a EP, principalmente os advindos do Ministério da Saúde. O Fundo de Alimentação e Nutrição (FAN) foi a fonte de recursos mais citada. Na fala a seguir, observa-se que o financiamento foi voltado para ações de capacitação.

A gente não tem dificuldades com relação à parte financeira não, porque a gente tem o recurso do Fundo de Alimentação e Nutrição, né, e dá para fazer essas capacitações. (CO3)

Para o alcance da melhoria das condições de alimentação e nutrição da população, é necessário garantir estratégias de financiamento tripartite para a implementação das diretrizes da PNAN, tendo, como uma das prioridades, a realização de processo de EP em alimentação e nutrição 
para trabalhadores de saúde 5 . O FAN foi criado em 2006 para apoiar a implantação das ações da PNAN e repassar recursos financeiros para municípios de grande porte.

Aspectos relacionados ao próprio profissional de saúde, como a adesão, na percepção dos coordenadores, também podem facilitar as ações de EP. Vale ressaltar, na fala a seguir, a ideia de treinamento para "repasse" de informações, com aplicabilidade no território.

Então, eles têm uma receptividade muito boa, quando a gente solicita para treinamento, mesmo os enfermeiros, o que eles querem, sabem que a gente está somando ao trabalho deles. É mais uma informação que eles vão ter, mais um treinamento que eles terão para atender àquela população, àquela comunidade, então acho que é só somar. (N1)

Serrão ${ }^{18}$, em seu estudo com profissionais de saúde da $\mathrm{AB}$ do Distrito Federal, retratou o interesse desses trabalhadores em realizar treinamentos, os quais foram considerados uma das fontes de informação mais importantes e adequadas sobre alimentação saudável. Também Silva ${ }^{19}$ apontou que os próprios profissionais relatam a necessidade de treinamentos. Entretanto, cabe a crítica de que se esses treinamentos forem ações pontuais, muitas vezes com temáticas escolhidas pelo gestor e deslocadas da realidade, poucos resultados terão em nível de mudanças de práticas e de alteração da própria organização do trabalho. Destaca-se novamente a importância de se instituir processos de EP, para o fortalecimento do planejamento das ações educativas.

NE4 traz o aspecto que ultrapassa os limites da EP, adentrando as questões da educação continuada, nesse caso, em nível de especialização, com incentivo às ações por parte da Secretaria Municipal de Saúde.

Houve um concurso, as nutricionistas se habilitaram ao concurso e as mais bem classificadas conseguiram as vagas e a Secretaria custeou a ida dessas nutricionistas a participar dessa especialização. (NE4)

Como apontam Costa et al. ${ }^{20}$, o conceito de EP se confunde ao de educação continuada, porém "esta permite o aprimoramento dos conhecimentos técnico-científicos como forma de promover uma prática centrada em particularidades ou especialidades de uma categoria profissional".

Outra ação que vem se mostrando importante nos processos educativos e que é incentivada pelo Ministério da Saúde é a formação de tutores para a multiplicação das ações educativas, que foi mencionada pelos entrevistados.
Já fizemos oficinas de trabalho (da Rede Amamenta Brasil) em algumas unidades, já fizemos oficinas para a formação de tutores aqui, no município. Pretendemos ampliar mais uma oficina, para a formação de mais tutores. (NE3)

Por fim, a presença de um setor de EP no município é outro importante fator facilitador. Novamente, o conceito de EPS se relaciona e se confunde com o de capacitação.

[...] nós temos, aqui, na secretaria, um setor de Educação Permanente, que esse setor é responsável por fazer essas capacitações dos profissionais da Estratégia Saúde da Família e, também, dos profissionais da Secretaria de Saúde como um todo. E lá, por meio dessa, desse setor, é onde a gente consegue fazer as capacitações. (NE3)

Segundo a Resolução do Conselho Federal de Nutricionistas $n^{\circ} 380 / 2005$, no âmbito da $A B$, o nutricionista deverá, necessariamente, participar do planejamento e execução de cursos de treinamento e aperfeiçoamento para profissionais da área de saúde e integrar polos de EP, visando o aprimoramento contínuo dos recursos humanos de todos os níveis do SUS ${ }^{21}$. Esses polos conformam-se como novas instâncias do sistema de saúde, reunindo gestores, instituições formadoras, profissionais de saúde e usuários do sistema, e têm sido propostos como modo de favorecer a articulação local/regional de todos os atores institucionais que são importantes para pensar e realizar a formação e o desenvolvimentos dos profissionais de saúde ${ }^{9}$.

\section{Fatores dificultadores para a Educação Permanente em alimentação e nutrição}

Em relação aos fatores dificultadores, foram identificadas oito subcategorias principais. O grande número de programas e atividades sob responsabilidade dos profissionais da ESF é o principal dificultador no que se refere ao equilíbrio de agendas para a realização das capacitações e do processo de EP. Torna-se complicado parar o atendimento dos usuários e disponibilizar tempo para os processos educativos mais formais. Esse aspecto foi bastante mencionado, principalmente nos municípios em que há NASF.

A maior dificuldade é tirar o profissional da unidade, visto que há um número crescente de programas ministeriais e o aumento da demanda das atividades. (NE2)

Além disso, as ações de alimentação e nutrição, muitas vezes, acabam ficando em segundo plano.

É, uma segunda coisa é porque também existem muitas ações na Atenção Básica e, nem sempre, esse 
lado da alimentação e nutrição, ele é visto como uma prioridade. Sempre outras ações se sobrepõem à alimentação e nutrição, como, por exemplo, na questão da dengue. Então todos os profissionais têm que ir à capacitação da dengue. "Não, é a questão, agora, né, da Influenza", então todos os profissionais são obrigados a ir para a Influenza. Então, outras várias ações vão se sobrepondo, com prioridade sobre a alimentação e nutrição. (NE3)

Esse fator dificulta a mudança de um modelo de atenção à saúde pautado na assistência e no curativismo, para um modelo voltado à promoção da saúde e prevenção de doenças ${ }^{22}$. A nova práxis na gestão da saúde precisa romper com as prioridades imediatistas fragmentadas e buscar equidade e justiça social, realizando ações intersetoriais e transversais em todas as áreas do governo $^{18}$.

A falta de profissionais na gestão das ações de alimentação e nutrição também apareceu em grande parte das falas, em especial dos municípios que não têm NASF. Chama atenção, nesse aspecto, que, dos coordenadores das ações de alimentação e nutrição entrevistados, apenas 19 eram nutricionistas. A escassez de recursos humanos prejudica a periodicidade das ações e a continuidade do processo de EP.

Como eu falei, às vezes, tem unidades que ficam duas vezes por ano, porque os recursos humanos nossos, aqui na secretaria, estão escassos e não temos como estar em todas as unidades trimestralmente, mas, normalmente, a gente costuma fazer com essa frequência. (NE5)

A falta de nutricionistas é mencionada como dificultador para a realização das ações mais básicas, como palestras. Essa dificuldade fica ainda mais intensa quando se pensa de forma mais ampla nos processos de trabalho cotidianos nas Unidades Básicas.

Esse número (de nutricionistas) é insuficiente até para a gente poder fazer uma capacitação com eles, palestras [...]. (NE8)

Cervato-Mancuso et al. ${ }^{23}$ também verificaram que o grau de inserção desse profissional ainda é insuficiente na $\mathrm{AB}$, tanto na ESF, com a inserção dos nutricionistas no NASF, quanto nas unidades básicas tradicionais, sendo que muitas equipes da $\mathrm{AB}$ não contam com esse apoio técnico. Assim, esses profissionais têm, como desafio, a atenção a uma população numerosa, prejudicando a efetividade das ações de alimentação e nutrição.

A própria ausência de uma estratégia de EP estruturada foi mencionada como entrave. Também a rotatividade de profissionais torna-se um empecilho à qualificação profissional na área de alimentação e nutrição, principalmente da classe médica.

Então assim, um empecilho que há é a rotatividade, principalmente da parte médica, né? Porque muitos vão fazer residência e acabam saindo. Então há uma quebra no serviço, né? (CO3)

Além de trazer dificuldades aos processos de $\mathrm{EP}$, a rotatividade profissional traz prejuízo a uma importante característica da ESF, que é o vínculo entre a população atendida e a equipe de saúde ${ }^{24}$.

Ainda nesse sentido, a adesão dos profissionais, mencionada por alguns entrevistados como fator facilitador, foi citada por outros como fator dificultador.

Alguns vêm, porque tem interesse em trabalhar naquilo que tem atuação na Atenção Básica, outros não têm interesse, não participam. (N2)

A questão dos médicos, em especial, foi retratada.

A gente sente em relação sempre à reclamação do médico, a gente sente em relação ao médico. Sempre que a gente vai procurar o médico, reunir médico é difícil, médico nunca tem tempo, médico nunca pode. Então, a gente tem esta dificuldade a mais com os médicos. (N1)

Também questões administrativas e financeiras têm sido apontadas como entraves. Uma delas é a questão dos trâmites para gastar o dinheiro. Há recursos financeiros, porém, muitas vezes, não são gastos devido a dificuldades burocráticas.

Uma das dificuldades é gastar esse dinheiro, então não tem verba orçamentária no município. Quer dizer, a verba está lá, mas eu não consigo, muitas vezes, é, gastar essa verba com algumas ações, porque o município tem todos os trâmites, né, financeiros. Eu até entendo, mas são alguns entraves... (S3)

Por fim, a falta de infraestrutura também dificulta o desenvolvimento da $\mathrm{EP}$, tanto em relação ao espaço físico para a realização de capacitações, quanto em relação ao transporte para a supervisão das ações.

Olhe, em relação à supervisão, é questão de recursos humanos mesmo na unidade e muitas vezes o transporte, para a gente estar se deslocando. A gente, assim, às vezes, a gente tem a supervisão marcada, mas aí está com problema no transporte, o carro está na oficina, aquela coisa toda que termina sabe, né? (NE5)

Acho que precisávamos ter, na saúde, locais apropriados para dar mais cursos práticos aos profissionais, e as unidades não contemplam isso. Nós temos que contar com espaços na comunidade, que nem sempre éfácil. (SE6) 
Situação semelhante é apontada por Cotta et al., ${ }^{24}$ que destacam a falta de infraestrutura como dificultador para a realização das ações dos profissionais da ESF, como a falta de transporte e de material, a precariedade da infraestrutura da unidade de saúde e a escassez de recursos financeiros.

Em relação à formação dos profissionais, algumas dificuldades foram apontadas pelos entrevistados para a concretização das ações na ESF e do NASF e dos processos de EP.

Agora, a Nutrição, a não ser agora, que seja um novo modelo que o NASF está incluindo esse profissional para a Estratégia Saúde da Família, mas até então, ele não tinha essa formação (para trabalhar com grupos). Tanto psicólogo quanto educador físico. Então, realmente eles tiveram bastante dificuldade, né. Eles me diziam assim: "Mas eu não consigo enxergar". (S1)

Orienta-se que cursos de graduação e pósgraduação na área de saúde, em especial de $\mathrm{Nu}$ trição, devem contemplar a formação de profissionais que atendam às necessidades sociais em alimentação e nutrição e que estejam em sintonia com os princípios do SUS e da PNAN ${ }^{5}$.

Entretanto, apesar dos problemas de saúde emergentes demandarem a atuação de profissionais que saibam identificar e abordar problemas relacionados à alimentação, essas questões ainda são pouco trabalhadas nos outros cursos de graduação na área da saúde ${ }^{25}$.

As dificuldades relacionadas à formação dos profissionais não se limitam à área de alimentação e nutrição, mas são bem mais amplas, o que traz prejuízos à própria $\mathrm{AB}$.

Hoje, as faculdades, as instituições acadêmicas, elas não formam os profissionais com esses olhares, existe uma evolução. Hoje, existem muitas universidades que estão mudando esse panorama, mas, em geral, o profissional não é formado para olhar para a comunidade, ele é formado com uma visão mercantilista, capitalista, para trabalhar no seu consultório, entendeu? Para ganhar o seu dinheiro, [...] (NE4)

Apesar de o quadro de saúde da população brasileira apontar para a necessidade de se realizarem ações voltadas para a promoção da saúde e prevenção de doenças, o modelo positivista da saúde continua a valorar as práticas curativas e a incentivar as especializações durante os cursos de formação em saúde, em detrimento do investimento em conteúdos disciplinares com foco no cuidado integral da saúde da população, como, por exemplo, o aspecto alimentar e nutricional ${ }^{19}$.

Por fim, também foi trazida à tona a relação entre teoria e prática, com a dificuldade de se aplicar no trabalho o que é visto nas ações educativas.

Até o próprio pessoal da unidade, às vezes, reclama que a gente faz esses, esses treinamentos, essas oficinas, mas aí, eles ficam, assim, meio que de mãos atadas, porque, muitas vezes, a família não tem realmente a condição de seguir aí, então, condição social mesmo, na condição social que a gente esbarra mais para a gente conseguir realmente elencar, efetivar essa questão da alimentação saudável. (NE5)

É por essa razão que a Política Nacional de Educação Permanente em Saúde (PEPS) ${ }^{7}$ orienta que os processos de EP sejam desenvolvidos a partir da realidade vivenciada pelo profissionais de saúde no serviço e não sobre temas pontuais e deslocados do cotidiano. Só relacionando realmente a teoria e a prática será possível transformar as práticas e os processos de trabalho.

\section{Estratégias para a Educação Permanente em alimentação e nutrição}

Em relação às estratégias utilizadas para a EP, foram identificadas nove subcategorias principais. A principal estratégia mencionada foi a realização de ações educativas a partir do nível local, o que vai ao encontro do preconizado na $\mathrm{PNAN}^{5}$ e na PEPS?

E nós estamos sempre, estamos, é, estamos revendo agora a forma de fazer essas capacitações e tentando fazer localmente e não mais centralizando [...] (S4)

[...] houve, recentemente, uma integração do SISVAN do Bolsa Família ao nosso sistema próprio e todos os treinamentos são feitos in loco. No cronograma, em todo o município, os treinamentos são feitos em in loco. (CO4)

Coutinho et al. ${ }^{26}$ reforçam que a agenda única da nutrição deve ser organizada pela caracterização clara do perfil epidemiológico da comunidade, com a identificação de riscos, problemas, prioridades, potencialidades e possibilidades de atuação e reconhecimento da situação de saúde, alimentação e nutrição das famílias. Para isso, deve-se fazer uso dos diversos sistemas de informação da AB, entre eles o Sistema de Vigilância Alimentar e Nutricional, que servirão de base tanto para a realização do diagnóstico em nível local, quanto para a tomada de decisão em diferentes níveis de governo.

O planejamento e a programação foram outras estratégias bastante mencionadas. CO4 cita o planejamento anual. Porém, é necessário um 
planejamento em torno de um processo de EP rotineiro baseado nas necessidades e não a programação apenas de ações pontuais, longe da realidade dos profissionais e da comunidade.

Essas capacitações, elas ocorrem através de um planejamento anual, que é feito nas ações. Todas as ações de alimentação e nutrição do município, elas partem de um planejamento integrado, anual, e delas saem também as propostas de capacitação para o ano. (CO4)

As ações educativas por grupos também são estratégias utilizadas para a $\mathrm{EP}$, inclusive com foco nos ACS, que representam uma grande parte dos profissionais.

[...] vai ser por grupos e não vai ser por módulos, vai ser por grupos. Turmas, portanto, que você possa, que a gente possa estar cobrindo todo esse quantitativo de novecentos e setenta agentes comunitários de saúde. (NE10)

Outra estratégia, recomendada pela PNAN e pela PEPS e apontada pelos entrevistados, foi a realização de avaliação e monitoramento.

No ano passado, que a gente mudou um pouquinho essas capacitações. Em vez de ser uma capacitação, de reunir profissionais para relembrar a execução das ações de nutrição, nós optamos pela ação de monitoramento do cumprimento das ações que eles já tinham conhecimento. (NE11)

A EP dos profissionais requer investimentos orientados para o desempenho dos serviços e para a vulnerabilidade social dos problemas de saúde, o que facilita o direcionamento das práticas para o monitoramento e o acompanhamento criterioso de indivíduos mais vulneráveis. Assim, a implantação de grupos locais de avaliação e monitoramento de saúde, bem como a qualificação de profissionais das unidades básicas, são benéficas para os serviços ${ }^{27}$.

Ao encontro do que é preconizado pela EP, em alguns municípios já são identificadas ações visando à conciliação da ação educativa teórica e do apoio técnico, assim como o feedback para os profissionais.

[...] a gente tem capacitado, tanto teoricamente, para as ações que a gente precisa desenvolver e para atividades do dia a dia, quanto também, que é uma forma de capacitar, é o subsidio técnico. (SE4)

E aí, eu mostro o quanto a gente tem conseguido fazer, porque (senão) eles se sentem muito um registrador de informação e ação. (NE11)

Facchini et al. ${ }^{27}$ também mencionam a questão do trabalho burocrático nas UBS, raramente informatizados, que ocupam parte importante do tempo dos profissionais de saúde, em detrimento de suas atividades-fim. O retorno e a dis- cussão dos dados com a equipe que os registram é importante para que se perceba a importância das ações de monitoramento de indicadores.

Por fim, o uso de metodologias ativas mais ativas também tem se mostrado como uma importante estratégia para o fortalecimento dos processos de EP.

Eu acho que é se aproximando cada vez mais, é permitindo, aprendendo, é construindo junto. Eu tenho estimulado, eu acredito muito na metodologia que vocês têm adotado para a pesquisa de vocês, que é da roda de conversa do grupo focal, de construir a partir da necessidade do outro. Eu não vou conhecer a necessidade do outro se não envolver o outro no processo, né. (NE11)

Paulo Freire destaca a importância da problematização para o encontro, nas ideias, de um sentido de inserção crítica na realidade, para dela retirar os elementos que conferirão significado e direção às aprendizagen ${ }^{28}$. O diálogo é uma forma de exercício de autonomia, pois não ocorre na forma de transmissão de conhecimento, mas sim sob a forma de instigação mútua. O exercício da autonomia nas práticas educativas é concretizado na relação ativa com o conhecimento, que possibilita um conjunto de decisões que se vai tomando ao longo da existência. Trabalhar em favor da autonomia é condição para que as práticas no campo da $\mathrm{AB}$ e, especialmente, da promoção da saúde, se configurem como educativas ${ }^{29}$.

Como aponta $\mathrm{Ceccim}^{8}$, para que o local de trabalho seja, de fato, um local de atuação crítica, reflexiva, propositiva, compromissada e tecnicamente competente, é necessário que haja a descentralização e a disseminação da capacidade pedagógica por dentro do setor, entre seus trabalhadores; entre gestores de ações, serviços e sistemas de saúde; entre trabalhadores e gestores com os formadores; e entre trabalhadores, gestores e formadores com o controle social em saúde, para que assim o SUS se constitua, verdadeiramente, como uma rede-escola.

\section{Conclusão}

Ao realizar a análise dos fatores facilitadores e dificultadores, verifica-se que, embora os municípios e os coordenadores das ações de alimentação e nutrição estivessem envolvidos com iniciativas de capacitações, alguns não se reconheciam em um projeto de natureza permanente, com espaços de reflexão de suas práticas diárias. Segundo os entrevistados, o cenário das Secretarias Municipais de Saúde, mesmo em cidades de grande por- 
te, possui limitações em colocar a EP como parte integrante dos seus planos e como palco de processo prático formativo. Muitos reconhecem que as demandas assistenciais exigem maior tempo da atenção das unidades básicas e de todo o seu modo de se organizar. Isso deixa os profissionais muito frágeis e suas agendas passam a se tornar um lugar propício ao "fazer rotinizado", fragilizando assim suas práticas orientadas pelo saber. Também a escassez de profissionais aptos ao desenvolvimento das ações reforça essa dificuldade.

Entretanto, veem, no projeto de EP, uma oportunidade capaz de contribuir com a reversão dessa lógica organizativa pautada somente na doença. Percebe-se, nas falas dos entrevistados, que, apesar das dificuldades, há uma necessidade de se inserir em um projeto de EP e um desejo de que a gestão possa assegurar as condições para a efetividade desse projeto. Com isso, será possível potencializar o conhecimento e as práticas dirigidas à gestão e à atenção nas ações de alimentação e nutrição.

Nesse sentido, já se tem avançado, com alguns fatores que facilitam o desenvolvimento de ações de EP, como as parcerias e os recursos direcionados para essa finalidade. Também estratégias, como a realização a partir do nível local, considerando as necessidades dos profissionais e da comunidade, com planejamento e apoio técnico, vêm sendo pensadas e realizadas.

Espera-se que, no futuro próximo, os "novos" gestores possam tomar para si a decisão de inserir todos os profissionais da ESF e do NASF em um projeto político pedagógico de EP, transformando as unidades básicas em cenários de produção do conhecimento em saúde e espaços instituídos para o aprofundamento de uma consciência sanitária, onde todos ensinam e aprendem, pelo bem dos indivíduos, das famílias e das comunidades.

\section{Colaboradores}

LM Ricardi participou de todas as etapas de elaboração do artigo. MF Sousa participou da concepção, do desenho e da revisão crítica do artigo.

\section{Agradecimentos}

Agradecemos ao Núcleo de Estudos de Saúde Pública, ao Observatório de Políticas de Segurança Alimentar e Nutrição e a todos os pesquisadores que fizeram parte da elaboração da pesquisa e da coleta e do processamento dos dados. 


\section{Referências}

1. Brasil. Ministério da Saúde (MS). Secretaria de Atenção à Saúde. Departamento de Atenção Básica. Política Nacional de Atenção Básica. Brasília: MS; 2012.

2. Sousa MF, Hamann EM. Programa Saúde da Família no Brasil: uma agenda incompleta? Cien Saude Colet 2009; 14(Supl. 1):1325-1335.

3. Assis AMO, Santos SMC, Freitas MCS, Santos JM, Silva MCM. O Programa Saúde da Família: contribuições para uma reflexão sobre a inserção do nutricionista na equipe multidisciplinar. Rev Nutr. 2002; 15(3):255-266.

4. Brasil. Ministério da Saúde (MS). Secretaria de Atenção à Saúde. Departamento de Atenção Básica. Matriz de ações de alimentação e nutrição na atenção básica de saúde. Brasília: MS; 2009.

5. Brasil. Ministério da Saúde (MS). Secretaria de Atenção à Saúde. Departamento de Atenção Básica. Política Nacional de Alimentação e Nutrição. Brasília: MS; 2012.

6. Eaton CB, McBride PE, Gans KA, Underbakke GL. Teaching nutrition skills to primary care practitioners. $J$ Nutr 2003; 133(2):563S-566S.

7. Brasil. Ministério da Saúde (MS). Secretaria de Gestão do Trabalho e da Educação na Saúde. Departamento de Gestão da Educação em Saúde. Política Nacional de Educação Permanente em Saúde. Brasília: MS; 2009.

8. Ceccim RB. Educação Permanente em Saúde: descentralização e disseminação de capacidade pedagógica na saúde. Cien Saude Colet 2005; 10(4):975-986.

9. Merhy EE, Feuerwerker LCM, Ceccim RB. Educación permanente en salud: una estrategia para intervenir en la micropolítica del trabajo en salud. Salud Colectiva 2006; 2(2):147-160.

10. Yin RK. Estudo de caso: planejamento e métodos. Porto Alegre: Bookman; 2001.

11. Bardin L. Análise de conteúdo. $5^{\mathrm{a}}$ ed. Lisboa: Edições 70; 2009.

12. University of Durham Information Technology Service. Introduction to NVivo. Duhram: University of Durham; 2011.

13. Ceccim RB, Feuerwerker LCM. O quadrilátero da formação para a área da saúde: ensino, gestão, atenção e controle social. Physis 2004, 14(1):41-65.

14. Silva ROB, Alves ED, Carvalho DSL, Mesquita DM. Programa PET-Saúde: trajetória 2009-2010, na Universidade de Brasília. Saúde debate 2012; 36(95):678-683.

15. Ferraz L. O PET-Saúde e sua interlocução com o PróSaúde a partir da pesquisa: o relato dessa experiência. Rev. bras. educ. med. 2012; 36(Supl. 1):166-171.

16. Recine E, Vasconcellos AB. Políticas nacionais e o campo da Alimentação e Nutrição em Saúde Coletiva: cenário atual. Cien Saude Colet 2011; 16(1):73-79.

17. Galvão EA, Sousa MF. As escolas técnicas do SUS: que projetos político-pedagógicos as sustentam? Physis 2012; 22(3):1159-1189.

18. Serrão SA. A promoção da alimentação saudável na Atenção Básica do Distrito Federal: a importância e a adequação das fontes de informação na perspectiva dos profissionais de saúde [dissertação]. Brasília: Universidade de Brasília; 2011.
19. Silva DO. O conhecimento, atitudes e práticas de profissionais de saúde da Atenção Básica sobre a promoção da alimentação saudável no Distrito Federal [tese]. Brasília: Universidade de Brasília; 2002.

20. Costa VZ, Cezar-Vaz MR, Cardoso LS, Soares JFS. Educação Permanente no Programa Saúde da Família: um estudo qualitativo. Invest Educ Enferm 2010; 28(3):336344.

21. Resolução no 380 de 2005. Dispões sobre a definição das áreas de atuação do nutricionista e suas atribuições, estabelece parâmetros numéricos de referência, por área de atuação, e dá outras providências. Conselho Federal de Nutricionistas 2005; 28 dez.

22. Paim J, Travassos C, Almeida C, Bahia L, Macinko J. The Brazilian health system: history, advances, and challenges. Lancet 2011;377(9779):1778-1797.

23. Cervato-Mancuso AM, Tonacio LV, Silva ER, Vieira VL. A atuação do nutricionista na Atenção Básica à Saúde em um grande centro urbano. Cien Saude Colet 2012; 17(12):3289-3300.

24. Cotta RMM, Schott M, Azeredo CM, Franceschini SCC, Priore SE, Dias G. Organização do trabalho e perfil dos profissionais do Programa Saúde da Família: um desafio na reestruturação da Atenção Básica em saúde. Epidemiol. Serv. Saúde 2006; 15(3):7-18.

25. Boog MCF. Dificuldades encontradas por médicos e enfermeiros na abordagem de problemas alimentares. Rev Nutr. 1999; 12(3):261-272.

26. Coutinho JG, Gentil PC, Toral N. A desnutrição e obesidade no Brasil: o enfrentamento com base na agenda única da nutrição. Cad Saude Publica 2008; 24(supl. 2):332-340.

27. Facchini LA, Piccini RX, Tomasi E, Thumé E, Silveira DS, Siqueira FV, Rodrigues MA. Desempenho do PSF no Sul e no Nordeste do Brasil: avaliação institucional e epidemiológica da Atenção Básica à Saúde. Cien Saude Colet 2006; 11(3):669-681.

28. Freire P. Pedagogia da autonomia: saberes necessários à prática educativa. São Paulo: Paz e Terra; 1996.

29. Carneiro ACLL, Souza V, Godinho LK, Faria ICM, Silva KL, Gazzinelli MF. Educação para a promoção da saúde no contexto da atenção primária. Rev Panam Salud Publica 2012; 31(2):115-120.

Artigo apresentado em 27/10/2013

Aprovado em 02/03/2014

Versão final apresentada em 05/03/2014 